\title{
Analysis and Review of Average Fuzzy Inference Technique and Other AI Techniques Used for Robot Control and Navigation
}

\author{
Parhi Dayal $\mathbf{R}^{1 *}$ and Sat Chidananda ${ }^{2}$ \\ ${ }^{1}$ NIT, Rourkela, India \\ ${ }^{2} D P S$, Rourkela, India \\ *Corresponding author: Parhi Dayal R, NIT Rourkela, India
}

\begin{abstract}
In this paper application of average fuzzy inference technique has been analysed for navigation control of robotic agent. Also, the reviews of other AI techniques for control of robots are carried out. The robotic agent uses sensors to map the surroundings and take the decision with the help of Fuzzy AI technique to avoid obstacles. In this paper a novel averaging method has been deployed to optimize the results obtained from various fuzzy membership functions. Using the Average Fuzzy Inference technique robot navigates from start position to goal position avoiding obstacles while reaching the target. The simulation results agree with experimental results. The methodology can be used for various applications by the scientific communities to address various engineering problems.
\end{abstract}

Keywords: Robot; Artificial intelligence; Control; Navigation; Average fuzzy inference

\section{Introduction}

Scientists throughout the world are working on various AI techniques to address control strategies of robots. The works done by various researchers to navigate and control robots in various environmental conditions are given below. Navigation of mobile robots using various AI techniques in highly cluttered environments while avoiding obstacles have been reported in [1-4]. AI techniques [5-8] are found to be suitable for robot's navigation control. In Ant Colony optimization technique, rate of pheromones deposition and evaporation have been used mathematically for getting a methodology to address various optimization problems in engineering and scientific fields. Papers [9-11] have elaborated Ant Colony optimization technique for control of mobile robots in various complex environments. The authors have carried out various types of exercises to corroborate their claimed methodology. Control of 7-degree redundant manipulator has been analysed in paper [12] .Bacteria foraging methodology [13-14] has been used by scientists for motion planning of humanoid type robots. Hybrid Differential
Evolution Algorithm [15] and Cuckoo Search Algorithm [16-17] have been discussed for solving various engineering problems by researchers. Researchers have used Dayani AI [18] method to control two wheeled mobile robots in an unknown environment. Using Daykun-Bip virtual target AI method [19] robots can find the targets in a highly cluttered environment. Fuzzy logic [20-24] is one of the robust artificial intelligence techniques used for solving various engineering problems. Various scientist has used fuzzy logic [25-28] to navigate robots in highly cluttered environments. Mobile robots can use fuzzy inference technique [29-33] for selfautonomous control in complex environments. Finite element analysis [34-37] can be utilized for evaluating the mechanical properties of various structures used for fabricating bodies and frames of the robots. Nature driven Fire Fly algorithm is one of the promising AI technique to address many optimization problems. Engineers have used Fire Fly algorithm [38-40] for path planning of robotic agents in uncertain environments. Fuzzy Inference 
technique has been hybridized with neural network technique to obtain Neuro-Fuzzy technique[41-46]. Many researchers have used Fuzzy-Neuro [47-51] techniques in the modern time for handling optimization problems also for finding optimized paths for robotic agents in highly cluttered unknown environments.

Flower Pollination Algorithm (FPA) and Bat Algorithm (BA) in combination have been discussed in the paper [52] for finding optimized path of robot in obstacles prone environments. Gait analysis has been discussed in the paper [53] for movement pattern of the robots. Genetic Algorithm [54-57] is one of the efficient AI technique for finding solutions for various engineering problems. Paper [58] discussed about the suitable use of Genetic Algorithm for Intelligent Robot control. Researcher has used Harmonic Search [59] algorithm for finding out optimal solution. Immune system has been mathematically encoded, to get Artificial Immune system [6062] and are subsequently used for solving complex optimization applications. Papers [63-65] have discussed about Artificial Immune System for navigation control of robots in complex environments. Paper [66] has discussed about invasive optimization technique as path planner for mobile robot navigation. Paper [67-70] have discussed about the kinematic analysis of various types of robots so that they can be applied in practical fields. Paper [71-72] have discussed about mobile computing techniques using artificial intelligence technique. Evolution of Brain is one of the important links in biological evolution. This is due to evolution of network consisting of neurons. Papers [73-77] have discussed about neural networks for navigational control of mobile robots in highly cluttered environments. Neural networks [78-82] can be efficiently used for solving various engineering problems along with problems related to robots' control. Potential energy attraction has been used by scientists and engineers to model artificial intelligence potential field method for solving various engineering problems. Papers [8384] have discussed about the use of artificial potential field method to address control of robot in various environments. Particle Swarm Optimisation (PSO) is one of the robust natures driven artificial intelligence technique for solving various complex optimisation problems. PSO [85-87] has been used efficiently to handle various robot control related problem in uncertain environments. Real time navigation for mobile robot has been address in the paper [88] subjected to unknown environment. Statistical Regression based analysis [89-91] has been used to analyse robot dynamics subjected various situations. Use of artificial intelligence techniques for robot control and path planning has been discussed in papers [92-93]. Rule based algorithms [94-95] are derived from various mathematical functions. They can be used successfully for various robotic control tasks. Simulated Algorithm [96] has a high potential and has been used by researchers to handle various robot control. Various engineering optimisation problems can be solved by soft computing methods. Many engineers have used soft computing methods [9798] for solving various robot control related problems. Nature inspired swarm intelligence technique [99-103] has been used for solving robot navigational problems. Scientists and engineers have used various methods to analyse crack identification [104-111] in vibrating structures. Papers [112-125] discuss about novel neural network and fuzzy logic to address problem of crack identification in complicated dynamic structures. Papers [126-129] discuss about hybrid AI techniques for robot control.

\section{Analysis of Average Fuzzy Inference Technique}

The paper uses Average Fuzzy Inference Technique for Robot Control. For average fuzzy technique two sets of membership functions (Triangular and Trapezoidal) are used. The inputs to the fuzzy inference systems are various sensors inputs (such as Left Obstacle Distance-LOS; Right Obstacle Distance-ROS and Front Obstacle Distance-FOS). The output is the average steering angle calculated from the Steering Angle (SA) of Fuzzy Inference Technique-1 (Consists of Triangular Membership Functions) and Fuzzy Inference Technique-2 (Consists of Trapezoidal Membership Functions). Figure 1 shows the architecture of the Average Fuzzy Inference System. Figure 2 shows the Simulation Path and Experimental Path for Khepera-II mobile robot [130] from start to goal. Table 1 shows the simulation and experimental path length and time taken. The deviation of Path length and time taken are to be found within $2 \%$.

Table 1: Simulation and Experimental Path Length and Time Taken.

\begin{tabular}{|c|c|c|c|c|}
\hline $\begin{array}{c}\text { Path Length } \\
\text { (Simulation) }\end{array}$ & $\begin{array}{c}\text { Path Length } \\
\text { (Experimental) }\end{array}$ & \% Deviation of Path & $\begin{array}{c}\text { Time Taken } \\
\text { (Simulation) }\end{array}$ & $\begin{array}{c}\text { Time Taken } \\
\text { (Experimental) }\end{array}$ \\
\hline $149 \mathrm{~cm}$ & $152 \mathrm{~cm}$ & $2 \%$ & 2792 Milli Seconds & $2850 \mathrm{Milli}$ Seconds \\
\hline
\end{tabular}




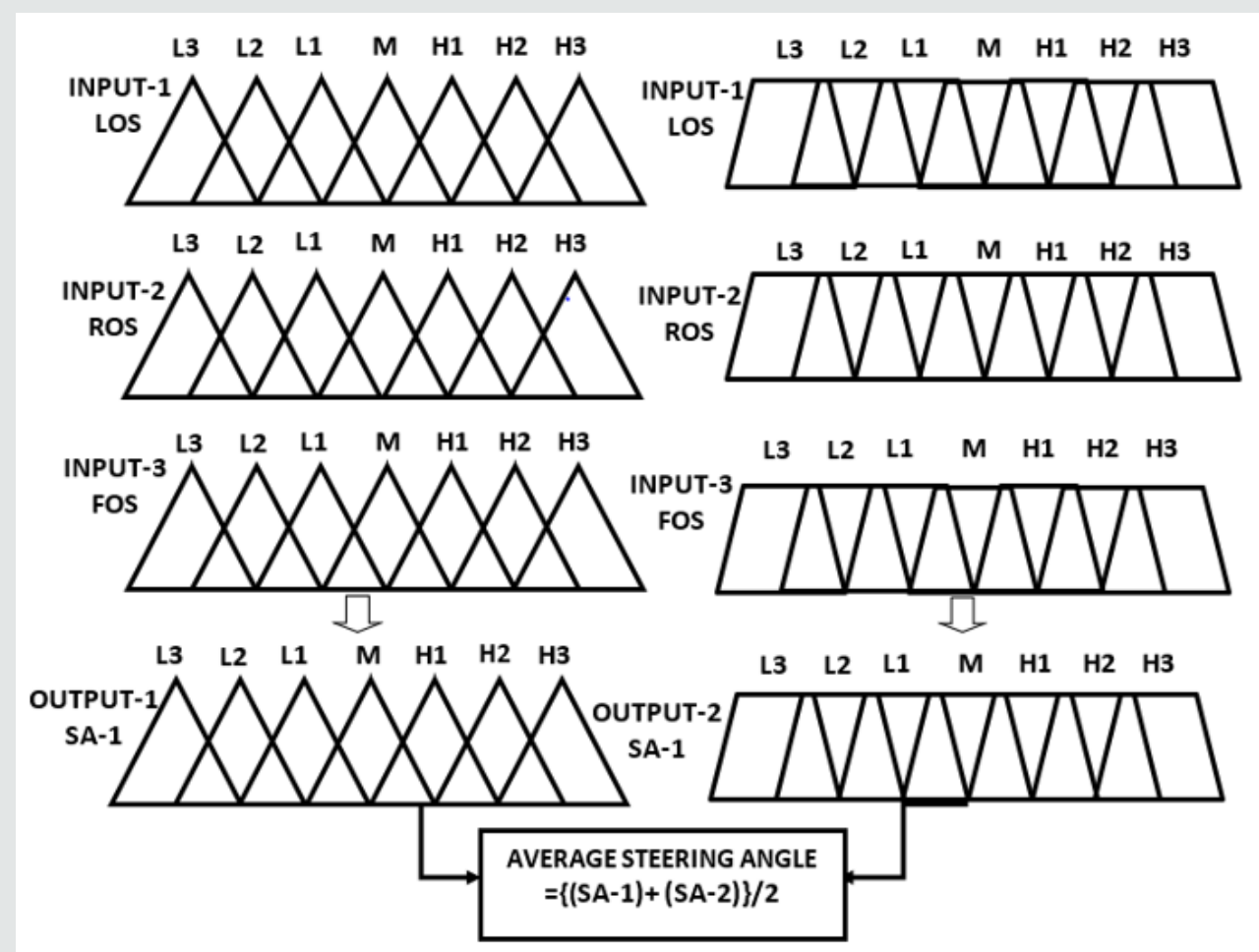

Figure 1: Architecture of Average Fuzzy Inference System.
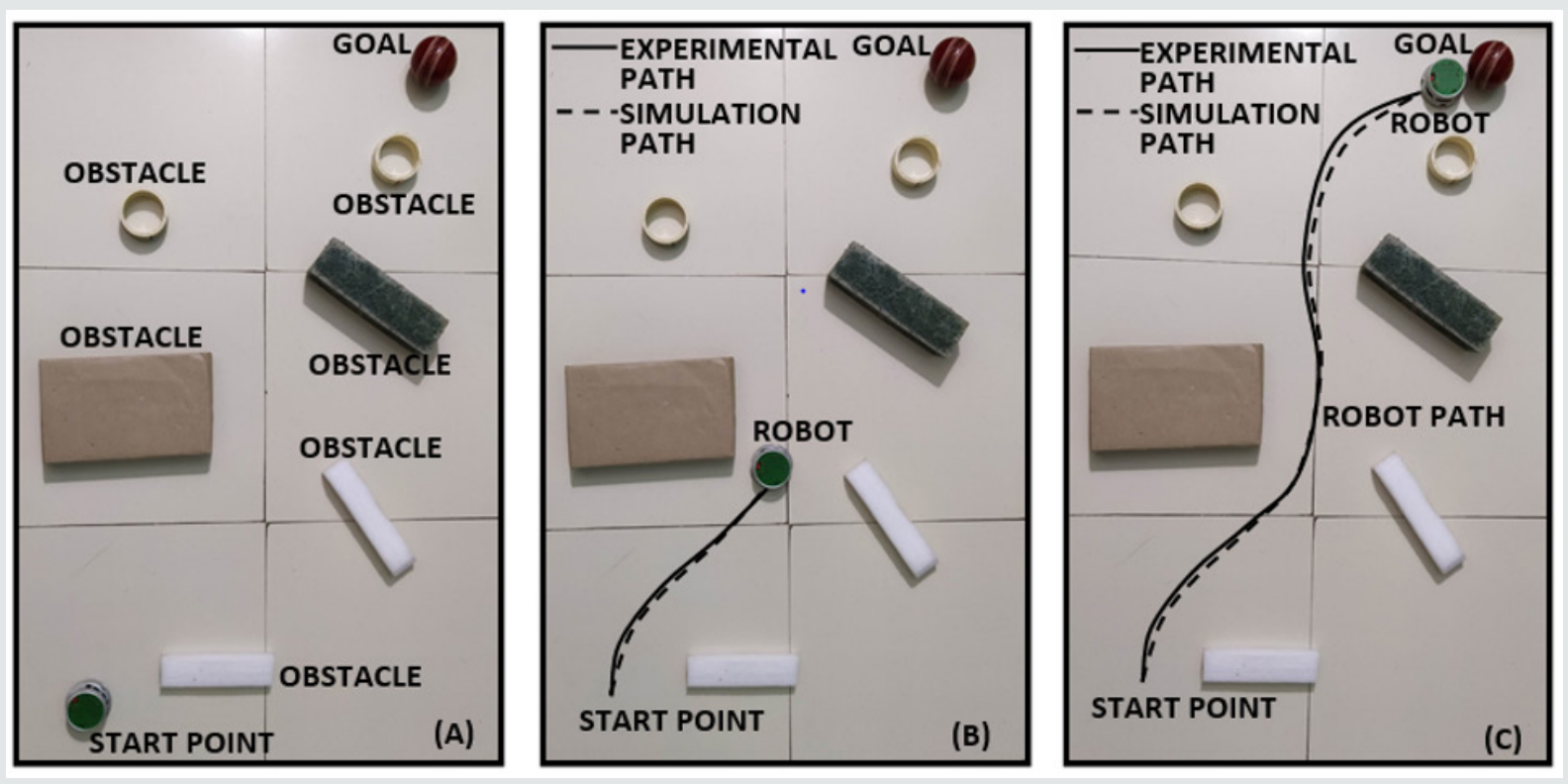

Figure 2: Simulation and Experimental Result of Khepera-II Robot from Start to Goal Point.

\section{Conclusion}

From the above analysis and reviews on mobile robots the following conclusions are drawn. From the analysis it is concluded that using average fuzzy inference technique robot can negotiate with obstacles and reach the target efficiently. The results are compared in simulation and experimental modes and the deviation between them is found to be within $2 \%$. During the review of papers, it has been found that artificial intelligence technique can be used efficiently for solving various engineering problems and robotic related problems. In the future more robust AI methods will be explored for solving robot navigation problem in efficient manner. 


\section{References}

1. Nasrinahar A, Chuah JH (2018) Intelligent motion planning of a mobile robot with dynamic obstacle avoidance. Journal on Vehicle Routing Algorithms 1(2-4): 89-104.

2. Wan J, Yang J, Wang Z, Hua Q (2018) Artificial intelligence for cloudassisted smart factory. IEEE Access 6(5): 5419-5430.

3. Rawat H, Parhi DR, Priyadarshi BK, Pandey KK, Behera AK (2018) Analysis and Investigation of Mamdani Fuzzy for Control and Navigation of Mobile Robot and Exploration of Different AI Techniques Pertaining to Robot Navigation. Emerging trends in Engineering, Science and Manufacturing (ETESM- 2018).

4. Dash AK, Parhi DR (2012) A vibration based inverse hybrid intelligent method for structural health monitoring. International Journal of Mechanical and Materials Engineering 6(2).

5. Sahu C, Kumar PB, Parhi DR (2018) An intelligent path planning approach for humanoid robots using adaptive particle swarm optimization. International Journal on Artificial Intelligence Tools 27(5): 1850015.

6. Kumar PB, Sethy M, Parhi DR (2019) An intelligent computer vision integrated regression-based navigation approach for humanoids in a cluttered environment. Multimedia Tools and Applications 78(9): 11463-11486.

7. Parhi DR, Mohanty PK (2012) A Study of various methodologies used for navigation of autonomous mobile robot. International Sci-ence Press: India 4(1): 19-26.

8. Pandey KK, Pol MS, Parhi DR (2014) Using an AI Technique Navigation and Path Planning for Mobile Robot on Webots Platform. IOSR Journal of Mechanical and Civil Engineering (IOSR-JMCE) p. 27-31.

9. Dai X, Long S, Zhang Z, Gong D (2019) Mobile robot path planning based on ant colony algorithm with $\mathrm{A}^{*}$ heuristic method. Frontiers in neurorobotics 13: 15.

10. Kumar PB, Sahu C, Parhi DR (2018) A hybridized regression-adaptive ant colony optimization approach for navigation of humanoids in a cluttered environment. Applied Soft Computing 68: 565-585.

11. Sahu C, Parhi DR, Kumar PB (2018) An approach to optimize the path of humanoids using adaptive ant colony optimization. Journal of Bionic Engineering 15(4): 623-635.

12. Kumar PB, Verma NK, Parhi DR, Priyadarshi D (2019) Design and control of a 7 DOF redundant manipulator arm. Australian Journal of Mechanical Engineering p. 1-12.

13. Kurdi H, Al Daood MF, Al-Megren S, Aloboud E, Aldawood AS, et al. (2019) Adaptive task allocation for multi-UAV systems based on bacteria foraging behaviour. Applied Soft Computing 83: 105643.

14. Muni MK, Parhi DR, Kumar PB (2020) Improved Motion Planning of Humanoid Robots Using Bacterial Foraging Optimization. Robotica p.114.

15. Sahu S, Kumar PB, Parhi DR (2019) Analysis of hybrid CSA-DEA method for fault detection of cracked structures. Journal of Theoretical and Applied Mechanics 57(2): 369-382.

16. Hosseininejad S, Dadkhah C (2019) Mobile robot path planningin dynamic environment based on cuckoo optimization algorithm. International Journal of Advanced Robotic Systems. 16(2): 1729881419839575.

17. Mohanty PK, Parhi DR (2013) Cuckoo search algorithm for the mobile robot navigation. International Conference on Swarm, Evolutionary, and Memetic Computing pp. 527-536.

18. Parhi DR, Chhotray A (2018) Development and analysis of DAYANI arc contour intelligent technique for navigation of two-wheeled mobile robot. Industrial Robot: An International Journal, Emerald Publishing Limited 45(5): 688-702.
19. Parhi DR, Kumar PB (2019) Smart navigation of humanoid robots using DAYKUN-BIP virtual target displacement and petri-net strategy. Robotica 37(4): 626-640.

20. Shi H, Xu M, Hwang KS (2019) A fuzzy adaptive approach to decoupled visual servoing for a wheeled mobile robot. IEEE Transactions on Fuzzy Systems.

21. Parhi DR, Mohanta JC (2011) Navigational control of several mobile robotic agents using Petri-potential-fuzzy hybrid controller. Applied Soft Computing 11(4): 3546-3557.

22. Singh MK, Parhi DR, Bhowmik S, Kashyap SK (2008) Intelligent controller for mobile robot: Fuzzy logic approach. The 12th International Conference of International Association for Computer Methods and Advances in Geomechanics (IACMAG) p. 1-6.

23. Mohanty PK, Parhi DR (2014) Navigation of autonomous mobile robot using adaptive network based fuzzy inference system. Journal of Mechanical Science and Technology, Korean Society of Mechanical Engineers 28(7): 2861-2868.

24. Parhi DR, Choudhury S (2011) Smart crack detection of a cracked cantilever beam using fuzzy logic technology with hybrid membership functions. Journal of Engineering and Technology research 3(8): 270278.

25. Parhi DR, Singh MK (2008) Intelligent fuzzy interface technique for the control of an autonomous mobile robot. Proceedings of the Institution of Mechanical Engineers, Part C: Journal of Mechanical Engineering Science 222(11): 2281-2292.

26. Rath AK, Parhi DR, Das HC, Muni MK, Kumar PB (2018) Analysis and use of fuzzy intelligent technique for navigation of humanoid robot in obstacle prone zone. Defence technology 14(6): 677-682.

27. Pandey A, Parhi DR (2014) MATLAB simulation for mobile robot navigation with hurdles in cluttered environment using minimum rule based fuzzy logic controller. Procedia technology 14(1): 28-34.

28. Mohanty PK, Parhi DR, Jha AK, Pandey A (2013) Path planning of an autonomous mobile robot using adaptive network based fuzzy controller. $20133^{\text {rd }}$ IEEE International Advance Computing Conference (IACC) pp. 651-656.

29. Mohanty S, Parhi DR, Das Ss S (2018) Control strategy of a real mobile robot using singleton takagi sugeno fuzzy inference methodology within the framework of artificial intelligence techniques. Emerging Trends in Engineering, Science and Manufacturing (ETESM-2018) pp. 576.

30. Panigrahi PK, Ghosh S, Parhi DR (2014) A Comparison of Mamdani and Sugeno Based Fuzzy Controller for Mobile Robot to Avoid Static Obstacles. In 5th International Elsevier Conference Electronics and Computer Science (IEMCON) pp. 226-231.

31. Mohanty S, Parhi DR, Das SS, Pradhan S (2018) Path Control Using Hybrid Mamdani Sugeno Fuzzy Controller for a Real Mobile Robot. International Journal of Applied Artificial Intelligence in Engineering System p. 1-21.

32. Mohanty S, Parhi DR, Das SS, Pradhan SK, Chhotray A, et al. (2018) Experimental Investigation on Traversed Path of Moving Robot Using Rule-Based-Fuzzy Integrated Method in a Densely Populated Environment. International Journal of Artificial Intelligence and Computational Research (IJAICR) 10(1): 33-49.

33. Deepak BB, Parhi DR (2019) New strategy for mobile robot navigation using fuzzy logic. In Information Systems Design and Intelligent Applications p. 1-8.

34. Khan IA, Parhi DR (2013) Finite element analysis of double cracked beam and its experimental validation. Procedia Engineering 51: 703708.

35. Parhi DR, Dash AK (2011) Application of neural network and finite element for condition monitoring of structures. Proceedings of the 
Institution of Mechanical Engineers, Part C: Journal of Mechanical Engineering Science 225(6): 1329-1339.

36. Jena PC, Parhi DR, Pohit G (2014) Theoretical, Numerical (FEM) and Experimental Analysis of composite cracked beams of different boundary conditions using vibration mode shape curvatures. International Journal of Engineering and technology 6(2): 509-518.

37. Parhi DR, Muni MK, Sahu C (2012) Diagnosis of Cracks in Structures Using FEA Analysis. International Science (IJAAIES) 4(1): 27-42.

38. Lagunes ML, Castillo O, Soria J, Garcia M, Valdez F (2019) Optimization of granulation for fuzzy controllers of autonomous mobile robots using the Firefly Algorithm. Granular Computing 4(2): 185-195.

39. Patle BK, Pandey A, Jagadeesh A, Parhi DR (2018) Path planning in uncertain environment by using firefly algorithm. Defence technology 14(6): 691-701.

40. Patle BK, Parhi DR, Jagadeesh A, Kashyap SK (2017) On firefly algorithm: optimization and application in mobile robot navigation. World Journal of Engineering 14(1).

41. Aouf A, Boussaid L, Sakly A (2018) TLBO-based adaptive neuro fuzzy controller for mobile robot navigation in a strange environment. Computational intelligence and neuroscience 2018.

42. Mohanty PK, Parhi DR (2015) A new hybrid optimization algorithm for multiple mobile robot's navigation based on the CS-ANFIS approach. Memetic Computing 7(4): 255-273.

43. Pandey A, Parhi DR (2016) Multiple mobile robots navigation and obstacle avoidance using minimum rule based ANFIS network controller in the cluttered environment. International Journal of Advanced Robotics and Automation 1(1): 1-11.

44. Singh MK, Parhi DR, Pothal JK (2009) ANFIS approach for navigation of mobile robots. In 2009 International Conference on Advances in Recent Technologies in Communication and Computing IEEE pp. 727-731.

45. Pandey A, Kumar S, Pandey KK, Parhi DR (2016) Mobile robot navigation in unknown static environments using ANFIS controller. Perspectives in Science 8: 421-423.

46. Mohanty PK, Parhi DR (2014) Path planning strategy for mobile robot navigation using MANFIS controller. In Proceedings of the International Conference on Frontiers of Intelligent Computing: Theory and Applications (FICTA) 2013 pp. 353-361.

47. Kundu S, Parhi DR, Deepak BB (2012) Fuzzy-neuro based navigational strategy for mobile robot. International Journal of Scientific \& Engineering Research 3(6): 1-6.

48. Parhi DR, Mohanty PK (2016) IWO-based adaptive neuro-fuzzy controller for mobile robot navigation in cluttered environments. The International Journal of Advanced Manufacturing Technology 83(9-12): 1607-1625.

49. Yadao AR, Parhi DR (2017) Dynamic Analysis of Fixed-Fixed Type Cracked Rotor in Viscous Medium. Journal of Vibration Engineering \& Technologies 5(6): 535-546.

50. Pandey A, Kashyap AK, Parhi DR, Patle BK (2019) Autonomous mobile robot navigation between static and dynamic obstacles using multiple ANFIS architecture. World Journal of Engineering 16(2).

51. Pradhan SK, Parhi DR, Panda AK (2006) Navigation of multiple mobile robots using rule-based neuro-fuzzy technique. International Journal of Computational Intelligence 3(2): 142-152.

52. Ghosh S, Panigrahi PK, Parhi DR (2017) Analysis of FPA and BA metaheuristic controllers for optimal path planning of mobile robot in cluttered environment. IET Science, Measurement \& Technology 11(7): 817-828.

53. Kashyap AK, Pandey A, Chhotray A, Parhi DR (2020) Controlled Gait Planning of Humanoid Robot NAO Based on 3D-LIPM Model.
54. Kwaśniewski KK, Gosiewski Z (2018) Genetic algorithm for mobile robot route planning with obstacle avoidance. acta mechanica et automatica 12(2): 151-159.

55. Sahu S, Parhi DR (2014) Automatic design of fuzzy MF using Genetic Algorithm for fault detection in structural elements. In 2014 Students Conference on Engineering and Systems 28: 1-5.

56. Rath AK, Parhi DR, Das HC, Kumar PB, Muni MK, et al. (2019) Path optimization for navigation of a humanoid robot using hybridized fuzzy-genetic algorithm. International Journal of Intelligent Unmanned Systems 7(3).

57. Behera SK, Parhi DR, Das HC (2018) Application of genetic algorithm for crack diagnosis of a free-free aluminum beam with transverse crack subjected to axial and bending load. Journal of Mechanical Engineering and Sciences 12(3): 3825-3851

58. Kumar PB, Parhi DR (2020) Navigational analysis of a humanoid using genetic algorithm with vision assistance. Multimedia Tools and Applications 3: 1-20.

59. Kundu S, Parhi DR (2016) Navigation of underwater robot based on dynamically adaptive harmony search algorithm. Memetic Computing 8(2): 125-146.

60. Cho S, Shrestha B, Jang W, Seo C (2019) Trajectory tracking optimization of mobile robot using artificial immune system. Multimedia Tools and Applications 78(3): 3203-3220.

61. Deepak BB, Parhi DR (2016) Control of an automated mobile manipulator using artificial immune system. Journal of Experimental \& Theoretical Artificial Intelligence 28(1-2): 417-439.

62. Deepak BB, Parhi DR (2013) Intelligent adaptive immune-based motion planner of a mobile robot in cluttered environment. Intelligent Service Robotics 6(3): 155-162.

63. Deepak BB, Parhi DR, Kundu S (2012) Innate immune based path planner of an autonomous mobile robot. Procedia Engineering 38: 2663-2671.

64. Parhi DR, Deepak BB, Mohana J, Ruppa R, Nayak M (2012) Immunised navigational controller for mobile robot navigation. Soft computing techniques in vision science pp. 171-182.

65. Deepak BB, Jha AK, Parhi DR (2011) Path planning of an autonomous mobile robot using artificial immune system. Int J Comput Math Sci 1: $1-6$.

66. Mohanty PK, Parhi DR (2014) A new efficient optimal path planner for mobile robot based on Invasive Weed Optimization algorithm. Frontiers of Mechanical Engineering 9(4): 317-330.

67. Parhi DR, Deepak BB (2011) Kinematic model of three wheeled mobile robot. Journal of Mechanical Engineering Research 3(9): 307-318.

68. Parhi DR, Behera AK, Pandey KK, Chhotray A, Kumar PB, et al. (2018) Study and Analysis of Hybrid Genetic-Adaptive-Rule base Method for Path Control of Multiple Wheeled Mobile Robotic Agent. International Journal of Artificial Intelligence and Computational Research (IJAICR) $10(1): 17-32$

69. Deepak BB, Parhi DR (2011) Kinematic analysis of wheeled mobile robot. Automation \& Systems Engineering 5(2): 96-111.

70. Parhi DR, Kumar PB, Behera AK, Pandey KK, Chhotray A, et al. (2018) Contour Analysis of a Dynamic Robot in a Cluttered Environment using Genetic-Cuckoo Search Method. International Journal of Artificial Intelligence and Computational Research (IJAICR) 10(1): 51-66.

71. Elappila M, Chinara S, Parhi DR (2018) Survivable path routing in WSN for IoT applications. Pervasive and Mobile Computing 43: 49-63.

72. Elappila M, Chinara S, Parhi DR (2020) Survivability Aware Channel Allocation in WSN for IoT applications. Pervasive and Mobile Computing 61: 101107 
73. Huang H, Zhou J, Di Q Zhou J, Li J (2019) Robust neural network-based tracking control and stabilization of a wheeled mobile robot with input saturation. International Journal of Robust and Nonlinear Control 29(2): 375-392.

74. Parhi DR, Singh MK (2009) Real-time navigational control of mobile robots using an artificial neural network. Proceedings of the Institution of Mechanical Engineers, Part C: Journal of Mechanical Engineering Science 223(7): 1713-1725.

75. Pham DT, Parhi DR (2003) Navigation of multiple mobile robots using a neural network and a Petri Net model. Robotica21(1): 79.

76. Mohanty JR, Verma BB, Parhi DR, Ray PK (2009) Application of artificial neural network for predicting fatigue crack propagation life of aluminum alloys. Association of Computational Materials Science and Surface Engineering 1(3): 133-138.

77. Das SS, Parhi DR, Mohanty S, Pradhan SK, Pandey KK, et al. (2018) Behavioural Study of Dynamic Robot During Path Planning in an Environment using Neural-Rule-Based Artificial Intelligence Technique. International Journal of Artificial Intelligence and Computational Research (IJAICR) 10(1): 1-16.

78. Rath AK, Das HC, Parhi DR, Kumar PB (2018) Application of artificial neural network for control and navigation of humanoid robot. Journal of Mechanical Engineering and Sciences 12(2): 3529-3538.

79. Pandey KK, Parhi DR (2020) Trajectory planning and the target search by the mobile robot in an environment using a Behavior-Based neural network approach. Robotica 38(9): 1627-1641.

80. Chhotray A, Parhi DR (2019) Navigational control analysis of twowheeled self-balancing robot in an unknown terrain using backpropagation neural network integrated modified DAYANI approach. Robotica 37(8): 1346-1362.

81. Jena PC, Parhi DR, Pohit G (2019) Dynamic Investigation of FRP Cracked Beam Using Neural Network Technique. Journal of Vibration Engineering \& Technologies 7(6): 647-661.

82. Nanda J, Das LD, Choudhury S, Parhi DR (2020) Revelence of Multiple Breathing Cracks on Fixed Shaft Using ANFIS and ANN. In Innovative Product Design and Intelligent Manufacturing Systems pp. 599-618.

83. Kumar PB, Rawat H, Parhi DR (2019) Path planning of humanoids based on artificial potential field method in unknown environments. Expert Systems 36(2): e12360.

84. Mohanta JC, Parhi DR, Patel SK, Pradhan SK (2016) Real-Time Motion Planning of Multiple Mobile Robots Using Artificial Potential Field Method. Journal of Advance Computational Research 1(1).

85. Deepak BB, Parhi DR (2012) PSO based path planner of an autonomous mobile robot. Open Computer Science 2(2): 152-168.

86. Panigrahi PK, Ghosh S, Parhi DR (2014) Comparison of GSA, SA and PSO based intelligent controllers for path planning of mobile robot in unknown environment. J Electr Comput Electron Commun Eng 8(10): 1523-1532.

87. Pandey A, Panwar VS, Hasan ME, Parhi DR (2020) V-REP-based navigation of automated wheeled robot between obstacles using PSOtuned feedforward neural network. Journal of Computational Design and Engineering.

88. Patle BK, Parhi DR, Jagadeesh A, Sahu OP (2017) Real Time Navigation Approach for Mobile Robot. JCP 12(2): 135-142.

89. Kumar PB, Sahu C, Parhi DR, Pandey KK, Chhotray A (2019) Static and dynamic path planning of humanoids using an advanced regression controller. Scientia Iranica 26(1): 375-393.

90. Kumar PB, Sahu C, Parhi DR (2020) Intelligent navigation of a selffabricated biped robot using a regression controller. Scientia Iranica 27(1): 262-272.
91. Kumar PB, Parhi DR (2020) Intelligent hybridization of regression technique with genetic algorithm for navigation of humanoids in complex environments. Robotica 38(4): 565-581.

92. Patle BK, Pandey A, Parhi DR, Jagadeesh A (2019) A review: On path planning strategies for navigation of mobile robot. Defence Technology 15(4): 582-606.

93. Parhi DR, Singh MK (2009) Navigational strategies of mobile robots: a review. International Journal of Automation and Control 3(2-3): 114 134.

94. Kumar SM, Kumar MD, Parhi DR, Prasad SM (2012) Intelligent controller for mobile robot based on heuristic rule base network. In Advanced Materials Research 403: 4777-4785.

95. Muni MK, Kumar PB, Parhi DR, Rath AK, Das HC, et al. (2020) Path Planning of a Humanoid Robot Using Rule-Based Technique. In Advances in Mechanical Engineering pp. 1547-1554.

96. Kashyap AK, Parhi DR, Kumar S (2020) Dynamic stabilization of NAO humanoid robot based on whole-body control with simulated annealing. International Journal of Humanoid Robotics 17(3): 2050014.

97. Parhi DR, Pradhan SK, Panda AK, Behera RK (2009) The stable and precise motion control for multiple mobile robots. Applied Soft Computing 9(2): 477-487.

98. Kumar PB, Muni MK, Parhi DR (2020) Navigational analysis of multiple humanoids using a hybrid regression-fuzzy logic control approach in complex terrains. Applied Soft Computing 89: 106088.

99. Ajeil FH, Ibraheem IK, Azar AT, Humaidi AJ (2020) Autonomous navigation and obstacle avoidance of an omnidirectional mobile robot using swarm optimization and sensors deployment. International Journal of Advanced Robotic Systems 17(3): 1729881420929498.

100. Parhi DR, Pothal JK, Singh MK (2009) Navigation of multiple mobile robots using swarm intelligence. In 2009 World Congress on Nature \& Biologically Inspired Computing (NaBIC) pp. 1145-1149.

101. Jena PK, Parhi DR (2015) A modified particle swarm optimization technique for crack detection in cantilever beams. Arabian Journal for Science and Engineering 40(11): 3263-3272.

102. Parhi DR, Sahu C, Kumar PB (2018) Navigation of multiple humanoid robots using hybrid adaptive swarm-adaptive ant colony optimisation technique. Computer Animation and Virtual Worlds 29(2): e1802.

103. Kumar PB, Sahu C, Parhi DR (2018) Navigation of humanoids by a hybridized regression-adaptive particle swarm optimization approach. Archives of Control Sciences 28(3): 349-378.

104. Agarwalla DK, Parhi DR (2013) Effect of crack on modal parameters of a cantilever beam subjected to vibration. Procedia Engineering 51: 665-669.

105. Behera RK, Pandey A, Parhi DR (2014) Numerical and experimental verification of a method for prognosis of inclined edge crack in cantilever beam based on synthesis of mode shapes. Procedia Technology 14: 67-74.

106. Thatoi DN, Das HC, Parhi DR (2012) Review of techniques for fault diagnosis in damaged structure and engineering system. Advances in Mechanical Engineering 4: 327569.

107. Parhi DR, Behera AK (1997) Dynamic deflection of a cracked beam with moving mass. Proceedings of the Institution of Mechanical Engineers, Part C: Journal of Mechanical Engineering Science 211(1): 77-87.

108. Das HC, Parhi DR (2009) Application of neural network for fault diagnosis of cracked cantilever beam. In 2009 World Congress on Nature \& Biologically Inspired Computing (NaBIC) pp. 1303-1308.

109. Jena PK, Thatoi DN, Nanda J, Parhi DR (2012) Effect of damage parameters on vibration signatures of a cantilever beam. Procedia engineering 38: 3318-3330. 
110. Parhi DR, Behera AK (1997) Dynamic deflection of a cracked shaft subjected to moving mass. Transactions of the Canadian Society for Mechanical Engineering 21(3): 295-316.

111. Jena PC, Parhi DR, Pohit G (2012) Faults detection of a single cracked beam by theoretical and experimental analysis using vibration signatures. IOSR Journal of Mechanical and Civil Engineering 4(3): 01 18.

112. Parhi DR, Kumar DA (2009) Analysis of methodologies applied for diagnosis of fault in vibrating structures. International Journal of Vehicle Noise and Vibration 5(4): 271-286.

113. Yadao AR, Singh RP, Parhi DR (2014) Influence of parameters of cracked rotor system on its vibration characteristics in viscous medium at finite region. In Applied mechanics and materials 592: 2061-2065.

114. Parhi DR, Agarwalla DK (2012) Determination of Modified Natural Frequencies of Fractured Fixed-Fixed Beam by Numerical \& Experimental Method. IJAAIES 4(2): 95-101.

115. Parhi DR, Behera AK (1998) The study of virtual mass and damping effect on a rotating shaft in viscous medium. Journal-Institution of Engineers India Part MC Mechanical Engineering Division pp. 109-113.

116. Nanda J, Das S, Parhi DR (2014) Effect of Slenderness ratio on crack parameters of simply supported Shaft. Procedia materials science 6: 1428-1435.

117. Jena SP, Parhi DR, Subbaratnam B (2017) Parametric evaluation on the response of damaged simple supported structure under transit mass. In Gas Turbine India Conference, American Society of Mechanical Engineers 58516: V002T05A003.

118. Parhi DR, Behera AK, Sahoo PK (1997) Dynamic Response of Beams with a Moving Mass. Journal-Aeronautical Society of India 49: 69-75.

119. Das HC, Parhi DR (2008) Modal analysis of vibrating structures impregnated with crack. International Journal of Applied Mechanics and Engineering 13(3): 639-652.

120. Parhi DR, Behera AK (1997) Vibration Characteristics of a Spinning Shaft in Viscous Liquid. JOURNAL-AERONAUTICAL SOCIETY OF INDIA 49: 174-179.
121. Kumar PB, Parhi DR (2017) Vibrational characteristics and stress analysis in a human femur bone. Materials Today: Proceedings 4(9): 10084-10087.

122. Jena SP, Parhi DR (2018) Dynamic response and analysis of cracked beam subjected to transit mass. International Journal of Dynamics and Control 6(3): 961-972.

123. Agarwalla DK, Parhi DR (2013) Diagnosis of Modal Characteristics of Aircraft Wing Model subjected to Irregularities. ijB 3: 1.

124. Jena SP, Parhi DR, Jena PC (2015) Dynamic Response of Damaged Cantilever Beam Subjected to Traversing Mass. International Journal for Technological Research in Engineering 2(7): 860-865.

125. Behera SK, Parhi DR, Das HC (2018) Numerical, experimental, and fuzzy logic applications for investigation of crack location and crack depth estimation in a free-free aluminum beam. Vibrations in Physical Systems 29.

126. Das SS, Parhi DR, Mohanty S, Pradhan SK, Chhotray A, et al. (2018) Analysis of Path Architecture of Mobile Robotic Platform with the Help of Cuckoo-Neuro Search Algorithm. International Journal of Artificial Intelligence and Computational Research (IJAICR) 10(1): 67-83.

127. Mohanty S, Parhi DR, Das SS, Pradhan SK, Pandey KK, et al. (2018) Motion and Track Analysis of a Several Wheeled Robot using Hybrid Genetic-Radial-Basis-Neural AI Technique Subjected to Different Environmental Conditions. International Journal of Artificial Intelligence and Computational Research (IJAICR) 10(1): 85-101.

128. Das SS, Parhi DR, Mohanty S, Kumar PB, Pradhan SK, et al. (2018) Path and Movement Study of a Biped Robot using Simulated-AnnealingNeural Method in the Presence of Target and Obstacles. International Journal of Artificial Intelligence and Computational Research (IJAICR) 10(1): 103-119.

129. Mohanty S, Parhi DR, Das SS, Pradhan SK, Pandey KK, et al. (2018) Target Finding and Obstacle Avoidance Behaviour Study of a Humanoid Robot with the Help of Embedded Hybrid Fuzzy-Immune Method. International Journal of Artificial Intelligence and Computational Research (IJAICR) 10(1): 121-137.

130. https://www.k-team.com/.

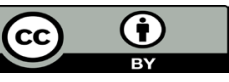

This work is licensed under Creative Commons Attribution 4.0 License

To Submit Your Article Click Here:

Submit Article

DOI: $10.32474 /$ CTCSA.2020.02.000129

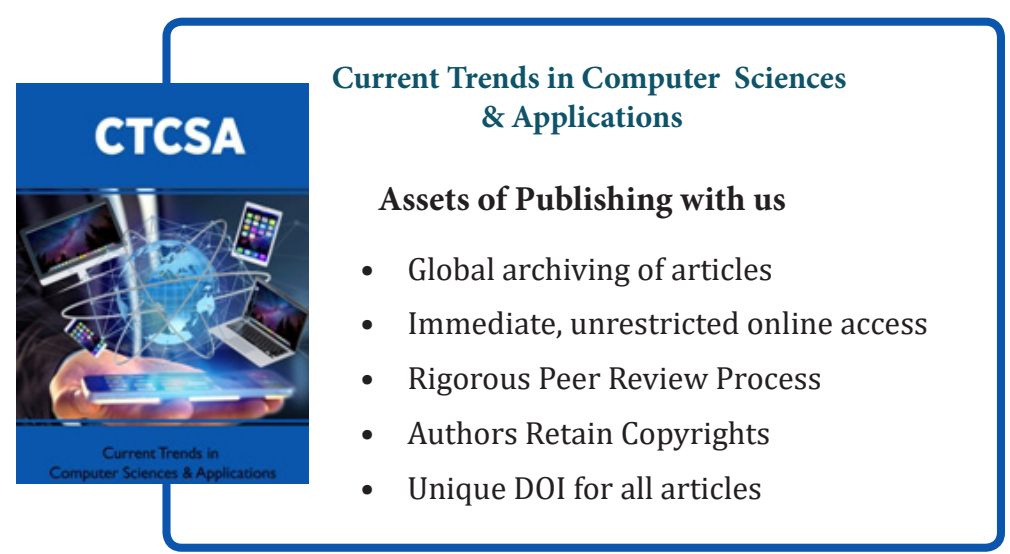

Citation: Parhi Dayal R, Sat Chidananda. Analysis and Review of Average Fuzzy Inference Technique and Other AI Techniques Used for 